\title{
A Text Messaging Intervention for Dietary Behaviors for People Receiving Maintenance Hemodialysis: A Feasibility Study of KIDNEYTEXT
}

Jessica Dawson, Westmead Clinical School, The University of Sydney, NSW, Australia; Centre for Kidney Research, The Children's Hospital at Westmead, Sydney, NSW, Australia; Nutrition and Dietetics Department, St George Hospital, Kogarah, Sydney, Australia PhD candidate, $M$ Nut\&Diet

Katrina L. Campbell, Menzies Health Institute, Griffith University; Allied Health Services, Metro North Hospital and Health Service Associate Professor, Health Services Research, PhD

Jonathan C. Craig, College of Medicine and Public Health, Flinders University, Adelaide, South Australia, Professor, Clinical Epidemiology, PhD

Allison Tong, Sydney School of Public Health, The University of Sydney, Sydney, NSW, Australia; Centre for Kidney Research, The Children's Hospital at Westmead, Sydney, NSW, Australia

Professor, Qualitative Health Research, PhD

Armando Teixeira-Pinto, Sydney School of Public Health, The University of Sydney, NSW, Australia; Centre for Kidney Research, The Children's Hospital at Westmead, Sydney, NSW, Australia

Professor, Biostatistics, PhD

Mark A Brown, Department of Renal Medicine. St George Hospital, Kogarah, Sydney, NSW, Australia; St George \& Sutherland Clinical School, University of New South Wales, Sydney, NSW, Australia.

Professor of Renal Medicine, $P h D$

Kirsten Howard, Sydney School of Public Health, The University of Sydney, NSW, Australia. Professor, Health Economics, PhD

Martin Howell, Sydney School of Public Health, The University of Sydney, NSW, Australia Research Fellow, Health Economics, PhD

Rabia Khalid, Westmead Clinical School, The University of Sydney, NSW, Australia Accredited Practicing Dietitian

Kamal Sud, Department of Renal Medicine, Nepean Hospital, Kingswood, NSW, Australia; Department of Renal Medicine, Westmead Hospital, Westmead, NSW, Australia; Nepean Clinical School, The University of Sydney, Sydney, NSW, Australia Clinical Associate Professor, Sydney Medical School, FRACP 
Aravinda Thiagalingam, Westmead Clinical School, The University of Sydney, NSW, Australia; Department of Cardiology, Westmead Hospital, Sydney, NSW, Australia.

Doctor, Cardiology, FRACP

Clara K Chow, Westmead Applied Research Centre, Westmead Clinical School, The University of Sydney, NSW, Australia; Department of Cardiology, Westmead Hospital, Sydney, NSW, Australia.

Professor, Sydney Medical School, PhD

Vincent W. Lee, Westmead Clinical School, The University of Sydney, NSW, Australia; Centre for Kidney Research, The Children's Hospital at Westmead, Sydney, NSW, Australia;

Department of Renal Medicine, Westmead Hospital, Westmead, NSW, Australia

Australia

Clinical Associate Professor, Sydney Medical School, PhD

\section{Correspondence to:}

Jessica Dawson, Centre for Kidney Research, The Children's Hospital at Westmead, Westmead, NSW 2145, Sydney, Australia

Email: jessica.dawson@ health.nsw.gov.au 


\section{ABSTRACT}

Rationale and Objective: An important component of hemodialysis management involves delivery of complex dietary recommendations. The aim of this study was to determine the feasibility of a mobile phone text message intervention to improve dietary behavior in people on hemodialysis.

Study design: Six-month randomized feasibility study.

Setting and participants: Patients receiving maintenance hemodialysis across two health districts in Sydney, Australia.

Interventions: Participants randomized to the intervention received three text messages per week, in addition to standard dietary care, for six months. The usual care group received standard dietary care.

Outcomes: The primary outcomes were feasibility, measured using recruitment and retention rates, acceptability of the intervention, and adherence to dietary recommendations. Secondary exploratory outcomes included information on certain clinical parameters related to dietary management of patients receiving maintenance hemodialysis.

Results: 130 people were recruited. $48 \%$ (130/272) of eligible patients consented to participate and $88 \%(115 / 130)$ completed the study. Semi-structured interviews evaluating acceptability identified five themes: clear and comprehensive, engaging with consistent and relevant content, maintaining attention with timely reminders, sustaining interest through ongoing care and generic messages inadequate to prompt dietary change. There was no difference in adherence to dietary recommendations across treatment groups (odds ratio: $1.21,95 \% \mathrm{CI} 0.55,2.72, \mathrm{p}=0.6$ ). Secondary exploratory analyses suggested reductions in dietary intake of single nutrients 
(potassium, phosphorus, sodium, protein), interdialytic weight gains, and phosphate binder usage among intervention participants compared to participants assigned to standard of care.

Limitations: Our feasibility study was of short duration. Adherence was based on self-reported data. Generalizability to populations receiving maintenance hemodialysis outside of an urban, Australian setting is unknown.

Conclusions: A simple mobile phone text messaging intervention was feasible and acceptable to patients. Further investigation of the impact on patient-reported and clinical outcomes is warranted.

Funding: Funding for the study was provided by a Sydney Medical School Foundation Grant and the Centre for Transplant and Renal Research at Westmead Hospital.

Trial Registration: ACTRN12617001084370

Key words: nutrition, diet, hemodialysis, mobile phone, technology, randomized controlled trial 


\section{PLAIN LANGUAGE SUMMARY}

Dietary management is a central component of care for people receiving hemodialysis. Mobile phone text messaging is widely used in the population and offers a potential avenue to enhance current nutritional care. KIDNEYTEXT was a 6-month randomised controlled study that evaluated the feasibility and acceptability of text messages to alter dietary behaviors. This intervention was feasible and acceptable. It showed promise at improving dietary parameters and may impact other clinically important outcomes, such as fluid management. Larger trials are needed to evaluate the effectiveness of this intervention. 


\section{INTRODUCTION}

Chronic kidney disease (CKD) affects approximately $13 \%$ of the population ${ }^{1,2}$. Dietary management plays an important role in preventing the progression of $\mathrm{CKD}$, managing complications such as high blood pressure, reducing symptom burden and managing electrolyte abnormalities. Patients with CKD have identified nutrition and lifestyle interventions as high priorities for research ${ }^{3}$.

Dietary management for people receiving hemodialysis is particularly challenging because patients have to integrate general healthy eating recommendations with additional complex and restrictive dietary requirements such as modifying protein, fluid, sodium, potassium, and phosphorus intake ${ }^{4}$. People receiving hemodialysis report that they lack the confidence and the skills to make dietary choices ${ }^{5-7}$. Whilst dietary self-management may be most effectively achieved through frequent, individualized education with a dietitian ${ }^{8,9}$, access to renal dietitians is variable, and may be limited ${ }^{10,11,12}$. Furthermore, one off didactic education sessions can be overwhelming and difficult to comprehend, particularly at the time of diagnosis ${ }^{6,7}$.

Given the high use of mobile phones and the internet, there is increasing interest in utilising these technologies to enhance nutritional care. In chronic disease populations, interventions using telehealth ${ }^{13}$ and mobile phone text messaging ${ }^{14}$ have led to improvements in dietary behaviors (e.g. increased fruit and vegetable intake and a reduction in sodium intake) and other clinical outcomes such as reductions in blood pressure, cholesterol levels and weight. The aim of 
this study was to evaluate the feasibility of a mobile phone text message intervention to improve dietary behavior in patients receiving hemodialysis.

\section{METHODS}

\section{Study design}

A detailed study protocol has been published ${ }^{15}$. In brief, we conducted a six-month randomized feasibility study, with a 2:1 allocation ratio. Outcome assessors were two external research dietitians who were blinded to allocation until the end of the study and who were not involved in any aspect of the participant's clinical care. The design and development of KIDNEYTEXT was underpinned by considerations for the development of complex interventions ${ }^{16}$ and a range of behavior change frameworks ${ }^{17}$ (Item S1). This study was approved by the Western Sydney Local Health District Human Research Ethics Committee and was registered with the Australian New Zealand Clinical Trials Registry (ACTRN12617001084370). Written and informed consent was obtained from all participants prior to their enrolment in the study.

\section{Study Setting}

The study was conducted in six dialysis units across two local health districts (Western Sydney and South-Eastern Sydney) Sydney, Australia. The dialysis units were included in the study serve socio-economically and culturally diverse populations. 


\section{Participants}

Eligibility criteria (Item S2) included end-stage kidney disease on maintenance hemodialysis for at least 90 days, age 18 years and over, having sufficient English language skills to read and understand text messages, and having access to a mobile phone throughout the duration of the study. Participants were randomly allocated using a computerized randomization program to either intervention or usual care (2:1), stratified by geographical location of the dialysis units (Western Sydney, South Eastern Sydney). Allocation was concealed from outcome assessors until the completion of the study. Participants were notified of their allocation via text message and were asked not to disclose their allocation to study personnel throughout the study.

\section{Intervention}

The usual care group continued to receive standard care provided by the dialysis unit. The intervention group received standard care plus three text messages per week over a 6-month period. Text messages were unidirectional, (i.e. one-way with no response required from participants). Unidirectional messages were chosen as these have been shown to improve dietary and lifestyle behaviors ${ }^{14}$ and are more time and cost-effective compared with in-person interventions. Content of the messages included advice, information, motivation and support to improve renal dietary behaviors (related to potassium, phosphorus, sodium, fluid) and general healthy eating and lifestyle behaviors. Text messages were semi-personalised based on baseline dietary intake and clinical parameters (Item S3) from baseline to 3 months. All intervention 
participants received general healthy eating and lifestyle messages from 4 months to 6 months. All participants had the opportunity to withdraw at any time via text message.

\section{Primary Outcomes}

The primary outcomes were feasibility, acceptability and adherence to dietary recommendations (Item S-4). Feasibility was measured using recruitment rate and retention rate. Adherence to dietary recommendations was defined as participants meeting three of the four dietary guideline recommendations with respect to protein, potassium, phosphorus, and sodium (Item S4).

Dietitians who served as outcome assessors and were blinded to participants' allocation and not involved with the clinical care of the participants assessed dietary intake, using the validated 24hour dietary recall methodology ${ }^{18}$. Prior to 3 and 6 month reviews participants were sent a text message reminding them not to reveal their allocation to the outcome assessors. Dietary recalls were conducted in-person or via telephone with food models to assist with portion size estimations, of both a dialysis day and a non-dialysis day, assessed at baseline, three months and six months. Dietary recalls included the intake of nutritional supplements. Dietary intake data was then analysed using Xyris Software Foodworks version 9 Pty Ltd (using food databases AUSNUT 2011-2013, Aus Foods 2017, Aus Brands 2017).

To determine acceptability and to undertake a process evaluation ${ }^{19}$ of the KIDNEYTEXT intervention we conducted semi-structured interviews with 25 participants sampled from the intervention group after completion of the 6 month follow-up. The process evaluation will be published separately. We undertook purposive sampling to achieve broad diversity of 
demographic and clinical characteristics. As we recruited participants, we monitored the characteristics and targeted recruitment of patients based on the demographic or clinical characteristics as required to obtain wide variability of responses. All interviews were audiorecorded and transcribed verbatim. Using principles of grounded theory and thematic analysis, J.S. coded the transcripts using HyperRESEARCH software (ResearchWare Inc. United States. Version 3.3) and inductively identified concepts. Investigator triangulation was undertaken whereby another investigator (A.Tong.) read the transcripts and discussed the preliminary themes to ensure these reflected the full range and depth of the data collected. Similar concepts were grouped into themes.

\section{Secondary exploratory outcomes}

Secondary exploratory outcomes (Item S4) included measurements at baseline, 3 months and 6 months of: mean change in renal-specific dietary nutrients, serum potassium, serum phosphate, interdialytic weight gain, dietary quality (measured using the Healthy Eating Index - HEI ${ }^{20}$ ), nutritional status, quality of life, blood pressure and additional serum markers (bicarbonate, urea, albumin, parathyroid hormone and for diabetics glycated hemoglobin), healthcare utilization (i.e. number of consultations with dietitian) and medication usage (Sodium Polystyrene Sulfonate, phosphate binders, diuretics, anti-hypertensives).

\section{Statistical analysis}

A sample size of 129 participants, 86 in the intervention arm and 43 in the usual care arm, provided $80 \%$ power to detect an increase from $25 \%$ to $50 \%$ (odds ratio of 3) or $90 \%$ power for an increase from $10 \%$ to $35 \%$ (odds ratio of 4.85 ) on adherence to renal dietary recommendations, using a chi-square test, with a significance level of 0.05 . Dietary adherence at 
6 months, was compared across the two groups with a logistic regression, adjusting for the stratification variable, local health district.

The secondary exploratory continuous outcomes were analysed as changes from baseline at 3 and 6 months, using linear models (separate models for each time period) and adjusting for the stratification variable - health district. For categorical variables, we have presented the adjusted odds ratios and the adjusted proportions for baseline status using the margins command from Stata $^{21}$. An additional analysis, presented as supplementary material (Item S5), analysed these outcomes longitudinally (baseline, 3 months, 6 months) through a linear mixed model with a random intercept for each participant and an interaction between time and trial arm. For secondary categorical outcomes, we used logistic models for each time point, adjusting for the baseline measurement and adjusted for the stratification variable. Similarly to the continuous variables, an additional analysis modelled these outcomes longitudinally (baseline, 3 months and 6 months), using a logistic mixed model with a participant-specific random intercept, adjusting for the stratification variable and including the interaction involving time and trial arm to compare the changes in the outcomes over time, between the two groups.

The $95 \%$ confidence intervals for means, proportions and odds ratios are model bases, unless stated otherwise. Missing data were not imputed and a complete case analysis was performed. The analysis was conducted in R software and SPSS. Dichotomous variables are summarized as numbers and percentages, continuous variables are presented as means and standard deviation (SD), or medians and 25th and 75th percentiles, according to their distribution.

\section{RESULTS}




\section{Feasibility}

A total of 462 individuals were screened, of whom 128 (28\%) were not eligible, $142(31 \%)$ declined to participate, $62(13 \%)$ were unable to be contacted or followed up and $130(28 \%)$ were recruited into the study from six centres between December 2017 and April 2018 (Figure 1). Reasons for being ineligible included not having access to a mobile phone $(24,19 \%)$, not having sufficient English (51, 40\%), having significant cognitive impairment (14, 11\%) and other $(39,30 \%)$. Reasons for declining to participate included not being interested $(62,43.5 \%)$, satisfied with current dietary care $(7,5 \%)$ and other, including non-disclosure of reason $(73$, $51.5 \%)$.

Of the eligible patients, 48\% (130/272) consented to participate. The rate of consent for each dialysis unit was between $32 \%$ to $58 \%$. Eighty-seven were randomized to receive the intervention and 43 randomized to usual care (Table 1). Among individuals who consented to participate, $88 \%(115 / 130)$ completed the study. Three intervention participants $(3 \%)$ requested text messages to be paused, reasons given included being too busy to read messages and having enough information. Nine participants in the intervention group (11\%) and six participants in the usual care group (14\%) did not complete the study. Reasons for not completing the study are shown in figure 1.

\section{Adherence to renal dietary guidelines}

At baseline, 28 intervention (34\%) and 18 usual care (46\%) participants were adherent with 3 or more dietary guidelines. At 6-months, 35 participants (45\%) were adherent in the intervention group compared with $15(41 \%)$ in the usual care arm (odds ratio: $1.21,95 \%$ CI $0.55,2.72, \mathrm{p}=0.6$ ) 
(Table 2, Figure 2). The result was the same when looking at the longitudinal measures of adherence (baseline, 3 months, and 6 months) in the logistic mixed model, adjusting for the stratification factor $(\mathrm{p}=0.1$ for the interaction between time and allocation).

\section{Acceptability}

Semi-structured interviews were conducted with 25 intervention arm participants at the completion of the study. Five themes were identified.

\section{Clear and comprehensive}

Participants found the text messages "informative" and "simple". The amount of repetition in the messages was deemed acceptable. Overall, they thought the messages covered a comprehensive range of dietary and lifestyle topics.

\section{Engaging with consistent and relevant content}

Participants felt that information in the text messages was relevant and reinforced previous educations. Text messages provided participants with a wider range of options of foods that they could include in their diet -"most of the information I'd been given previously...but there were a couple I didn't know...for example I didn't realise cottage cheese was preferred...(I have now) incorporated this" (Male, 80s, community dialysis).

\section{Maintaining attention with timely reminders}

Participants appreciated having regular reminders about their diet to "keep them on track". Three messages per week was thought to be "just right" to keep them engaged with the messages 
without becoming burdensome. Participants did not have a preference for what time of day, or day of the week the text messages were received. However, some preferred receiving the text messages while on dialysis or on a "dialysis day" - "Getting the messages while I was doing dialysis clicked off something in the back of my mind... If I had have got them on a (non-dialysis day) I don't think I would have taken any notice of them." (Male, 50s, in-centre).

\section{Sustaining interest through ongoing care}

Participants received text messages over a six-month period, which they perceived was adequate, and "looked forward to what (text message) was going to come up next" (Male, 60s, home dialysis). Some participants felt that receiving these messages when first commencing dialysis would have been helpful - "it would have been better because obviously it was all new to me" (Male, 80s, community dialysis).

\section{Generic messages inadequate to prompt diet change}

Some participants felt the messages were "too generic" and needed more individualised information to prompt them to "break their routines" and alter their diet. Ongoing consultation with renal dietitians was considered important by participants to receive more personalised information.

\section{Secondary exploratory outcomes}

Dietary intake: Dietary intake outcomes are summarized in Table 3 and Item S5. The intervention arm had a mean reduction in potassium intake of $7.4 \mathrm{mmol}(95 \% \mathrm{CI}-12.8,-2)$ 
compared to a slight increase in the usual care arm of $2.9 \mathrm{mmol}(95 \% \mathrm{CI}-4.5,10.3)$ to $59 \mathrm{mmol}$ $(\mathrm{p}=0.01)$. There was a mean reduction in dietary phosphorus intake in the intervention arm of 168mg (95\% CI -277, -58), and a slight increase in the usual care arm of $85 \mathrm{mg}$ (95\% CI -64, 235) $(\mathrm{p}=0.003)$. There was a mean reduction in sodium intake in the intervention arm of $-417 \mathrm{mg}$ (95\% CI -622, -210.6), with the usual care arm having a smaller mean reduction of $29 \mathrm{mg}(95 \%$ CI $-310,252)(\mathrm{p}=0.03)$. Mean protein intake declined in the intervention arm by $11 \mathrm{~g}(95 \% \mathrm{CI}-$ 18.7, -4.8$)$ and remained stable in the usual care arm $(1.1 \mathrm{~g}, 95 \% \mathrm{CI}-8.4,10.5)(\mathrm{p}=0.01)$. There was no difference in HEI score between the groups ( $\mathrm{p}=0.3)$ (Table 3).

Biochemical parameters: There was no difference or clinical meaningful change between intervention and usual care arms with respect to serum potassium, albumin, urea, bicarbonate, parathyroid hormone or HbA1c (Table 3, Item S5). Whilst there was no statistical difference in mean serum phosphate or the proportion of participants meeting serum phosphate guidelines, there was a clinically meaningful reduction in serum phosphate in the intervention arm by 0.19mmol/L (95\% CI -0.32, -0.06). (Table 3, Item S5).

Interdialytic weight gain: Participants receiving the intervention were significantly more likely to meet IDWG guidelines (OR 6.23, 95\% CI 2.12, 20.43, $\mathrm{p}=0.001$ ). There was a significant improvement in IDWG in the intervention arm $(-0.06 \mathrm{~kg}, 95 \% \mathrm{CI}-0.29,0.18)$ compared to usual care participants $(0.37 \mathrm{~kg}, 95 \%$ CI $0.04,0.69)(\mathrm{p}=0.022)$.

Quality of life: The quality of life at 6 months as measured by the EQ-5D utility score was lower in the intervention group with a mean reduction of 0.04 (95\% CI -0.10, 0.02) compared to usual 
care mean improving by $0.06(95 \%$ CI $-0.02,0.15)(\mathrm{p}=0.03)$. The variation in utility scores from baseline to 6 months was such that there was no difference in quality adjusted life years (QALYs) between the intervention $(0.39$ years, $95 \%$ CI $0.35,0.5)$ and usual care groups $(0.42$ years, $0.41,0.5)(\mathrm{p}=0.4)($ Table 3$)$.

Additional exploratory outcomes: There was a reduction in the mean number of phosphate binder medications in the intervention arm by 0.49 tablets $(95 \%$ CI $-1.19,0.22)$ and an increase in mean number of phosphate binder in the usual care arm by 0.71 tablets $(95 \% \mathrm{CI}-0.22,1.64)$ $(\mathrm{p}=0.03)$ (Table 3). There was no difference or clinically relevant change in nutritional status, the usage of other medications (Sodium Polystyrene Sulfonate, diuretics, anti-hypertensives), blood pressure or number of dietetic consultations (Table 3). A detailed health economics evaluation will be published elsewhere.

\section{DISCUSSION}

A simple mobile phone text intervention targeting dietary behaviors is feasible. There was a high rate of recruitment and retention, with $48 \%$ of eligible people consenting to be involved in the study, $88 \%$ of participants completed the study, with only $2 \%$ asking to be withdrawn from the study and $2 \%$ requesting text messages to be paused. Participants reported the intervention to be acceptable and were satisfied and engaged with the text messages.

The most significant barriers to recruitment into the study included not having access to a mobile phone, having insufficient English to read and understand text messages, not being interested in participating in research. These barriers are generally consistent with the literature regarding 
challenges of recruitment into nephrology studies ${ }^{22}$. Potential methods in which to improve recruitment in a future trial could be to design an adaptive, cluster (by dialysis unit) randomized study with the intervention embedded into current renal nutrition services to promote buy-in from clinicians and enrolling patients through trusted clinicians and enhancing the participation of dialysis staff in the development and implementation of the intervention ${ }^{22-24}$.

KIDNEYTEXT was deemed acceptable by participants with self-reported high levels of satisfaction and engagement. This has been reflected in another trial conducted in CKD, that used a combination of telephone consultations and mobile phone text messages $\left(\right.$ ENTICE) ${ }^{25}$. In both our study and ENTICE, participants reported the interventions to prompt dietary behavior change, and found the frequency of text messages and length of intervention satisfactory, with text message content being relevant and comprehensible. KIDNEYTEXT had a recruitment rate of $48 \%$ and a low withdrawal rate of $2 \%$. Similar findings have been reported in other studies using eHealth interventions to alter dietary behaviors, with $35 \%$ recruitment rate ${ }^{25}$ and $5 \%$ withdrawal rates ${ }^{25,26}$. These findings indicate a good uptake and acceptance of eHealth interventions in CKD and hemodialysis populations, and justifies the conduct of larger and longer duration trials to establish effects on long term outcomes.

The adherence definition in KIDNEYTEXT did not reach statistical significance. Our finding is in contrast to results from a prior study, TEXTME, which was a 6-month RCT conducted in coronary heart disease. ${ }^{14}$ TEXTME demonstrated significant improvements in dietary intake with use of a one-way mobile phone text messaging intervention. This study demonstrated significantly more intervention participants (93\%) adhered to 4 or more (out of 8) dietary 
guidelines, compared to usual care participants $(75 \%) .{ }^{27}$ There was no data available to guide a sample size calculation for dietary adherence for the KIDNEYTEXT study. The sample size calculation underestimated adherence to dietary guidelines in usual care. The KIDNEYTEXT study has provided useful data for future studies when considering dietary intake and dietary adherence as a primary end-point.

We detected some promising signals in secondary exploratory outcomes of KIDNEYTEXT that will need to be evaluated in future trials. The intervention group showed a progressive reduction in dietary sodium intake from baseline to 6 months. Consistent with these results, KIDNEYTEXT demonstrated a significant improvement in fluid management in intervention participants. There was a significant difference in average IDWG and the proportion of participants meeting IDWG targets at 6 months. Our findings are supported by results from prior studies. Interventions using digital self-monitoring tools, with or without individualised dietary counselling have been conducted in dialysis populations ${ }^{26,28}$ and showed modest reduction in average daily sodium intake of $197 \mathrm{mg}$ sodium daily (95\% CI -540.76 to $116.85 \mathrm{mg} / \mathrm{d}$ ) at 4 months ${ }^{29}$, however the strength of this evidence was considered to be low. A meta-analysis that demonstrated reduction of IDWG by an average of $0.13 \mathrm{~kg}$ per day $(95 \% \mathrm{CI}$ -0.27 to 0.01 ) in hemodialysis populations through self-monitoring eHealth interventions, however the evidence was considered to be of low quality ${ }^{29}$.

In KIDNEYTEXT, we noted an unintended decline in protein intake, with intervention participants reducing their protein intake and usual care participants maintaining their protein intake. Given the significant reduction in dietary phosphorus intake, this result is not unexpected 
as there is a large overlap in foods containing both protein and phosphorus. Whilst there was a significant reduction in protein intake in the intervention group there was no change in nutritional status in either study arm.

The quality of life in the KIDNEYTEXT group was not anticipated to be different to that of the usual care group given the short time frame of the study. Quality adjusted life years, collected for economic evaluations, accounts for the change in quality of life over follow-up of the study was the same between the two groups. The EQ-5D utility values in both the KIDNEYTEXT (0.7) and usual care (0.8) groups were higher than values commonly reported for people receiving hemodialysis ${ }^{30}$.

The strengths of KIDNEYTEXT include its randomized design that focused on feasibility evaluation of a simple mobile phone text messaging intervention to alter dietary behaviors in the hemodialysis population. There are some limitations to our study. Firstly, this was a small study of short duration. This study was designed to confirm feasibility, with our results indicating that text messages can produce dietary change and justifies the need for a larger study to confirm results and long-term acceptability and outcomes. Whilst participants were asked not to share messages, it is unknown whether participants shared text messages with patients who were in the control group that may have led to unintended change in behaviours (i.e. contamination). However, should this have occurred, the differences in dietary behaviors would likely be diluted. Additionally, dietary intake data was measured using patients' self-report. Self-reported dietary intake may not accurately reflect an individual's actual intake, however we used validated 24hour dietary recall methodology to standardise dietary intake assessment and minimise bias. 
Finally, generalizability to hemodialysis populations outside of an Australian, urban setting may vary depending upon the availability of specialist dietitians. Future trials should include measures to determine the impact on these outcomes.

Whilst further evaluation is needed confirm our findings, this study indicates that mobile phone text messaging is feasible and acceptable. This simple intervention has the potential to be used in everyday practice by dietitians and renal units to enhance current nutritional care, particularly in settings where access to renal dietitians is limited. Further evaluation of the impact of mobile phone text messaging in other CKD groups, (i.e. chronic kidney disease stages 3-5, conservative management, peritoneal dialysis and transplantation) is required. Our results suggest that phosphate and fluid management (assessed using IDWG) may be best targeted with supportive dietary text messages. KIDNEYTEXT indicated an improvement in the proportion of intervention participants meeting phosphate and IDWG guidelines by $15 \%$ and $17 \%$ respectively. This approaches the threshold of a $25 \%$ improvement in adherence that was determined to be clinically significant. Recommendations for the design of a larger clinical trial in hemodialysis are outlined in table 4.

Traditional (e.g. face-to-face) interventions to alter behaviors, such as dietary sodium intake ${ }^{31-33}$ and fluid management ${ }^{34}$ are resource-intensive, requiring frequent (e., g. weekly or fortnightly) contact with practitioners. In practice, access to renal dietitians may be limited, with dietitians citing a lack of resources to being able to provide adequate support and counselling ${ }^{10-12}$. In our study, at baseline less than $70 \%$ of participants had seen a dietitian in the past year and only half had seen a dietitian during the 6-month follow up. A simple, feasible and acceptable mobile 
phone text messaging intervention aimed at improving dietary behaviors in a hemodialysis population may be a useful interim measure used in conjunction with individualised face-to-face counselling. Our feasibility study justifies a larger RCT to evaluate the impact of a mobile phone text messaging intervention on important patient-centred and clinical outcomes in hemodialysis.

\section{SUPPLEMENTARY MATERIAL}

Item S1: Behavioural frameworks used to develop text messages

Item S2: Eligibility criteria

Item S3: Text message allocation (baseline to 3 months)

Item S4: Primary and secondary exploratory outcome measures

Item S5: Secondary exploratory outcomes longitudinally analysed from baseline to 6 months

\section{ARTICLE INFORMATION}

Authors' Contributions: principal investigators who designed study: VWL, KLC, JCC, ATong, JD; substantial contributions to the conception and design of the project: CKC, AThiagalingam, MAB, KH, MH, KS; developed the software for use in the study: AThiagalingam; collected data: JD, RK; performed statistical analysis: AT-P. Each author contributed important intellectual content during manuscript drafting or revision and agrees to be personally accountable for the individual's own contributions and to ensure that questions pertaining to the accuracy or integrity of any portion of the work, even one in which the author was not directly involved, are appropriately investigated and resolved, including with documentation in the literature if appropriate. 
Support: Funding for the study was provided by a Sydney Medical School Foundation Grant and the Centre for Transplant and Renal Research at Westmead Hospital. These funders had no role in study design, data collection, analysis, reporting, or the decision to submit for publication.

Financial Disclosure: K.S. has received speaker's honoraria from Baxter Healthcare, Roche, Amgen, and Boehringer Ingelheim, and conference or meeting sponsorships from Shire, Roche, Boehringer Ingelheim, Amgen, Sanofi, and Novartis. The remaining authors declare that they have no relevant financial interests.

Acknowledgements: All the authors acknowledge and are grateful for the support provided by patients, renal clinicians, and staff at The University of Sydney for assistance in the design of KIDNEYTEXT. The authors thank those renal clinicians who assisted in the implementation of KIDNEYTEXT and those patients who participated in the study.

Data Sharing: Individual participant data that underlie the results reported in this article, after de-identification will be made available beginning 9 months and ending 36 months following article publication. The study protocol has been published in detail ${ }^{15}$ and the statistical analysis plan uploaded to ANZCTR (www.anzctr.org.au). Investigators who provide a methodologically sound proposal and have gained ethical clearance may use the de-identified individual data as per the proposal. Proposals may be submitted up to 36 months following article publication by contacting vincent.lee@sydney.edu.au. Requestors will need to sign a data access agreement. After 36 months the data will be available in our Universities data warehouse but without investigator support other than deposited metadata. 
Peer Review: Received April 1, 2020. Evaluated by 2 external peer reviewers, with direct editorial input from a Statistics/Methods Editor, an Associate Editor, and the Editor-in-Chief. Accepted in revised form November 14, 2020.

\section{REFERENCES}

1. Levey AS, Coresh J, Balk E, et al. National Kidney Foundation Practice Guidelines for Chronic Kidney Disease: Evaluation, Classification, and Stratification. Ann Intern Med. 2003;139(2):137.

2. Hill NR, Fatoba ST, Oke JL, et al. Global Prevalence of Chronic Kidney Disease - A Systematic Review and Meta-Analysis. PloS one. 2016;11(7):e0158765.

3. Manns B, Hemmelgarn B, Lillie E, et al. Setting research priorities for patients on or nearing dialysis. Clin J Am Soc Nephrol. 2014;9(10):1813-1821.

4. Ash S, Campbell K, MacLaughlin H, et al. Evidence based practice guidelines for the nutritional management of chronic kidney disease. Nutr Diet. 2006;63:S33-S45.

5. Griva K, Ng HJ, Loei J, Mooppil N, McBain H, Newman SP. Managing treatment for endstage renal disease - A qualitative study exploring cultural perspectives on facilitators and barriers to treatment adherence. Psychol Health. 2013;28(1):13-29.

6. Palmer SC, Hanson CS, Craig JC, et al. Dietary and Fluid Restrictions in CKD: A Thematic Synthesis of Patient Views From Qualitative Studies. Am J Kidney Dis. 2015;65(4):559-573. 
7. Stevenson J, Tong A, Gutman T, et al. Experiences and Perspectives of Dietary Management Among Patients on Hemodialysis: An Interview Study. J Ren Nutr. 2018;28(6):411-421.

8. Karavetian M, de Vries N, Rizk R, Elzein H. Dietary educational interventions for management of hyperphosphatemia in hemodialysis patients: a systematic review and meta-analysis. Nutr Rev. 2014;72(7):471-482.

9. Desroches S, Lapointe A, Ratte S, Gravel K, Legare F, Turcotte S. Interventions to enhance adherence to dietary advice for preventing and managing chronic diseases in adults. Cochrane Database Syst Rev. 2013(2):Cd008722.

10. Hand RK, Steiber A, Burrowes J. Renal Dietitians Lack Time and Resources to Follow the NKF KDOQI Guidelines for Frequency and Method of Diet Assessment: Results of a Survey. J Ren Nutr. 2013;23(6):445-449.

11. Hall-McMahon EJ, Campbell KL. Have renal dietitians successfully implemented evidence-based guidelines into practice? A survey of dietitians across Australia and New Zealand. J Ren Nutr. 2012;22(6):584-591.

12. Burrowes JD, Russell GB, Rocco MV. Multiple factors affect renal dietitians' use of the NKF-K/DOQI Adult Nutrition Guidelines. J Ren Nutr. 2005;15(4):407.

13. Kelly JT, Reidlinger DP, Hoffmann TC, Campbell KL. Telehealth methods to deliver dietary interventions in adults with chronic disease: a systematic review and meta-analysis. Am J Clin Nutr. 2016;104(6):1693-1702.

14. Chow C, Redfern J, Hillis G. Effect of lifestyle-focused text messaging on risk factor modification in patients with coronary heart disease: a randomised clinical trial. Am Med Assoc. 2015;314(12):9. 
15. Stevenson J, Campbell KL, Brown M, et al. Targeted, structured text messaging to improve dietary and lifestyle behaviours for people on maintenance haemodialysis (KIDNEYTEXT): study protocol for a randomised controlled trial. BMJ Open. 2019;9(5).

16. Craig P, Dieppe P, Macintyre S, Michie S, Nazareth I, Petticrew M. Developing and evaluating complex interventions: the new Medical Research Council guidance. BMJ. $2008 ; 337$.

17. Abraham C, Michie S. A taxonomy of behavior change techniques used in interventions. Health Psychol. 2008;27(3):379-387.

18. Raper N, Perloff B, Ingwersen L, Steinfeldt L, Anand J. An overview of USDA's Dietary Intake Data System. J Food Compost Anal. 2004;17(3):545-555.

19. Moore GF, Audrey S, Barker M, et al. Process evaluation of complex interventions: Medical Research Council guidance. BMJ. 2015;350.

20. Australian Institute of Health and Welfare. Australian diet quality index project. Canberra 2007.

21. Williams R. Using the margins command to estimate and interpret adjusted predictions and marginal effects.(Report). Stata J. 2012;12(2):308.

22. Selewski DT, Herreshoff EG, Gipson DS. Optimizing Enrollment of Patients into Nephrology Research Studies. Clin J Am Soc Nephrol. 2016;11(3):512-517.

23. Baigent $\mathrm{C}$, Herrington $\mathrm{WG}$, Coresh $\mathrm{J}$, et al. Challenges in conducting clinical trials in nephrology: conclusions from a Kidney Disease-Improving Global Outcomes (KDIGO) Controversies Conference. Kidney Int. 2017;92(2):297-305. 
24. Natale P, Gutman T, Howell M, et al. Recruitment and retention in clinical trials in chronic kidney disease: report from national workshops with patients, caregivers and health professionals. Nephrol Dial Transplant. 2020;35(5):755-764.

25. Kelly JT, Warner MM, Conley M, et al. Feasibility and acceptability of telehealth coaching to promote healthy eating in chronic kidney disease: a mixed-methods process evaluation. BMJ Open. 2019;9(1).

26. Sevick MA, Piraino BM, St-Jules DE, et al. No Difference in Average Interdialytic Weight Gain Observed in a Randomized Trial With a Technology-Supported Behavioral Intervention to Reduce Dietary Sodium Intake in Adults Undergoing Maintenance Hemodialysis in the United States: Primary Outcomes of the BalanceWise Study. J Ren Nutr. 2016; 26(3):149-158

27. Santo K, Hyun K, de Keizer L, et al. The effects of a lifestyle-focused text-messaging intervention on adherence to dietary guideline recommendations in patients with coronary heart disease: an analysis of the TEXT ME study.(Report). Int J Behav Nutr Phys. $2018 ; 15(1)$.

28. Koprucki M, Piraino B, Bender F, et al. RCT of Personal Digital Assistant (PDA) supported dietary intervention to reduce sodium intake in PD [abstract]. Am J Kidney Dis. 2010;55(4):A72.

29. Stevenson J, Campbell Z, Webster A, et al. eHealth interventions for people with chronic kidney disease. Cochrane Database Syst Rev. 2019(8).

30. Wyld M, Morton RL, Hayen A, Howard K, Webster AC. A systematic review and metaanalysis of utility-based quality of life in chronic kidney disease treatments. PLoS medicine. 2012;9(9):e1001307-e1001307 
31. Rodrigues Telini L, Carvalho Beduschi G, Caramori J, Castro J, Martin L, Barretti P. Effect of dietary sodium restriction on body water, blood pressure, and inflammation in hemodialysis patients: a prospective randomized controlled study. Int Urol Nephrol. 2014;46(1):91-97.

32. Whelton PK, Appel LJ, Espeland MA, et al. Sodium Reduction and Weight Loss in the Treatment of Hypertension in Older Persons: A Randomized Controlled Trial of Nonpharmacologic Interventions in the Elderly (TONE). J Am Med Assoc. 1998;279(11):839-846

33. The Trials of Hypertension Prevention Collaborative Research G. Effects of Weight Loss and Sodium Reduction Intervention on Blood Pressure and Hypertension Incidence in Overweight People With High-Normal Blood Pressure: The Trials of Hypertension Prevention, Phase II. Arch Intern Med. 1997;157(6):657-667.

34. Bossola M, Pepe G, Vulpio C. The Frustrating Attempt to Limit the Interdialytic Weight Gain in Patients on Chronic Hemodialysis: New Insights Into an Old Problem. J Ren Nutr. 2018;28(5):293-301. 
Table 1: Baseline characteristics

\begin{tabular}{|c|c|c|}
\hline Characteristics & $\begin{array}{c}\text { Intervention } \\
\mathbf{n}=\mathbf{8 7}\end{array}$ & $\begin{array}{c}\text { Usual Care } \\
n=43 \\
\end{array}$ \\
\hline Sex (Male) & $50(57.5)$ & $29(67.4)$ \\
\hline Age, mean (SD) & $64.4(13.2)$ & $65.2(14.5)$ \\
\hline \multicolumn{3}{|l|}{ Cause of ESKD, n(\%) } \\
\hline Diabetes & $42(48.3)$ & $17(39.5)$ \\
\hline Hypertension & $5(5.7)$ & $9(20.9)$ \\
\hline Interstitial Nephritis & 0 & 0 \\
\hline Polycystic Kidney Disease & $6(6.9)$ & $1(2.3)$ \\
\hline Obstructive Nephropathy & 0 & $1(2.3)$ \\
\hline Reflux Nephropathy & $1(1.1)$ & 0 \\
\hline Autoimmune & $16(18.4)$ & $8(18.6)$ \\
\hline Other & $11(12.6)$ & $4(9.3)$ \\
\hline Undetermined & $6(6.9)$ & $3(7)$ \\
\hline Dialysis Vintage (years), mean (SD) & $3.2(3)$ & $2.8(2.9)$ \\
\hline \multicolumn{3}{|l|}{ Dialysis Location, $\mathbf{n}(\%)$} \\
\hline Western Sydney & $56(64.4)$ & $27(62.8)$ \\
\hline South East Sydney & $31(35.6)$ & $16(37.2)$ \\
\hline \multicolumn{3}{|l|}{ Dialysis Unit, n(\%) } \\
\hline Auburn Hospital & $9(10)$ & $5(12)$ \\
\hline Blacktown Hospital & $22(25)$ & $11(26)$ \\
\hline Nepean Hospital & $19(22)$ & $8(19)$ \\
\hline St George Hospital & $20(23)$ & $11(26)$ \\
\hline Sutherland Hospital & $11(13)$ & $5(12)$ \\
\hline Westmead Hospital & $6(7)$ & $2(5)$ \\
\hline \multicolumn{3}{|l|}{ Dialysis Type, $\mathbf{n}(\%)$} \\
\hline In-center & $15(17.2)$ & $5(11.6)$ \\
\hline Community-based & $66(75.9)$ & $34(79.1)$ \\
\hline Home & $6(6.9)$ & $4(9.3)$ \\
\hline \multicolumn{3}{|l|}{ Previous RRT, n(\%) } \\
\hline None & $71(81.6)$ & $36(83.7)$ \\
\hline Kidney transplant & $9(10.3)$ & 0 \\
\hline Peritoneal Dialysis & $7(8)$ & $7(16.3)$ \\
\hline \multicolumn{3}{|l|}{ Number of co-morbidities, $n(\%)$} \\
\hline Less than 3 & $52(59.8)$ & $24(55.8)$ \\
\hline 3 or more & $35(40.2)$ & $19(44.2)$ \\
\hline \multicolumn{3}{|l|}{ Cultural Background, n(\%) } \\
\hline Australia, New Zealand & $38(43.7)$ & $29(46.5)$ \\
\hline Aboriginal, Torres Strait Island & $5(5.7)$ & $1(2.3)$ \\
\hline Pacific Islands & $20(23)$ & $5(11.6)$ \\
\hline European & $11(12.6)$ & $2(4.7)$ \\
\hline North American & $1(1.1)$ & 0 \\
\hline South and Central Asian & $3(3.4)$ & $2(4.7)$ \\
\hline North-Eastern Asian & 0 & $1(2.3)$ \\
\hline South-East Asian & $4(4.6)$ & $2(4.7)$ \\
\hline Middle East, North Africa & $5(5.7)$ & $8(18.6)$ \\
\hline Sub-Saharan Africa & 0 & $2(4.7)$ \\
\hline \multicolumn{3}{|l|}{ Country of Birth, n(\%) } \\
\hline Australia & $46(52.9)$ & $19(44.2)$ \\
\hline Other & $41(47.1)$ & $24(55.8)$ \\
\hline \multicolumn{3}{|l|}{ Primary language, n(\%) } \\
\hline English & $67(77)$ & $23(53.5)$ \\
\hline Other & $20(23)$ & $20(46.5)$ \\
\hline Seen a dietitian prior to intervention, $n(\%)$ & $58(66.6)$ & $30(69.7)$ \\
\hline
\end{tabular}


Table 2: Proportion of participants adhering to renal dietary recommendations for hemodialysis

\begin{tabular}{|c|c|c|c|c|c|c|}
\hline & \multicolumn{2}{|c|}{ Baseline } & \multicolumn{2}{|c|}{3 months } & \multicolumn{2}{|c|}{6 months } \\
\hline & $\begin{array}{c}\text { Intervention } \\
\mathrm{n}=87\end{array}$ & $\begin{array}{c}\text { Usual care } \\
n=43\end{array}$ & $\begin{array}{c}\text { Intervention } \\
n=84\end{array}$ & $\begin{array}{c}\text { Usual care } \\
n=39\end{array}$ & $\begin{array}{c}\text { Intervention } \\
\mathrm{n}=78\end{array}$ & $\begin{array}{c}\text { Usual care } \\
n=37\end{array}$ \\
\hline Protein & $\begin{array}{l}37(43 \%) \\
(32 \%, 53 \%)\end{array}$ & $\begin{array}{l}15(35 \%) \\
(20 \% \\
50 \%)\end{array}$ & $\begin{array}{l}30(36 \%) \\
(26 \%, 47 \%)\end{array}$ & $\begin{array}{l}20(51 \%) \\
(35 \%, \\
68 \%)\end{array}$ & $\begin{array}{l}18(23 \%) \\
(14 \%, 33 \%)\end{array}$ & $\begin{array}{l}17(46 \%) \\
(29 \%, \\
63 \%)\end{array}$ \\
\hline Potassium & $\begin{array}{l}61(70 \%) \\
(60 \%, 80 \%)\end{array}$ & $\begin{array}{l}32(74 \%) \\
(61 \%, \\
81 \%)\end{array}$ & $\begin{array}{l}62(74 \%) \\
(65 \%, 84 \%)\end{array}$ & $\begin{array}{l}29(74 \%) \\
(60 \% \\
89 \%)\end{array}$ & $\begin{array}{l}65(83 \%) \\
(75 \%, 92 \%)\end{array}$ & $\begin{array}{l}27(73 \%) \\
(58 \% \\
88 \%)\end{array}$ \\
\hline Phosphorus & $\begin{array}{l}25(29 \%) \\
(19 \%, 38 \%)\end{array}$ & $\begin{array}{l}16(37 \%) \\
(22 \% \\
52 \%)\end{array}$ & $\begin{array}{l}22(26 \%) \\
(17 \%, 36 \%)\end{array}$ & $\begin{array}{l}10(26 \%) \\
(11 \%, \\
40 \%)\end{array}$ & $\begin{array}{l}32(41 \%) \\
(30 \%, 52 \%)\end{array}$ & $\begin{array}{l}11(30 \%) \\
(14 \%, \\
45 \%)\end{array}$ \\
\hline Sodium & $\begin{array}{l}61(70 \%) \\
(64 \%, 83 \%)\end{array}$ & $\begin{array}{l}29(67 \%) \\
(60 \% \\
89 \%)\end{array}$ & $\begin{array}{l}61(73 \%) \\
(64 \%, 83 \%)\end{array}$ & $\begin{array}{l}29(74 \%) \\
(60 \% \\
89 \%)\end{array}$ & $\begin{array}{l}63(81 \%) \\
(72 \%, 90 \%)\end{array}$ & $\begin{array}{l}27(73 \%) \\
(58 \% \\
88 \%)\end{array}$ \\
\hline $\begin{array}{l}\text { Adherent with } \geq 3 \\
\text { renal dietary } \\
\text { guidelines } * *\end{array}$ & $\begin{array}{l}28(32 \%) \\
(23 \%, 44 \%)\end{array}$ & $\begin{array}{l}18(42 \%) \\
(30 \% \\
63 \%)\end{array}$ & $\begin{array}{l}30(36 \%) \\
(26 \%, 47 \%)\end{array}$ & $\begin{array}{l}16(41 \%) \\
(25 \% \\
57 \%)\end{array}$ & $\begin{array}{l}35(45 \%)^{*} \\
(34 \%, 56 \%)\end{array}$ & $\begin{array}{l}15(41 \%)^{*} \\
(24 \% \\
57 \%)\end{array}$ \\
\hline
\end{tabular}

Data is presented as $\mathrm{n}(\%)$ (95\% confidence intervals)

$* \mathrm{p}=0.6$ for the comparison between the two arms, adjusting for geographical location of dialysis unit (stratification variable), using a logistic regression,

** $\mathrm{p}=0.1$ for interaction of time and allocation, in the longitudinal analysis (secondary analysis), adjusting for local health district (stratification variable) 
Table 3: Secondary exploratory outcomes. Changes from baseline to three and six months

\begin{tabular}{|c|c|c|c|c|c|}
\hline & & \multicolumn{2}{|c|}{$\begin{array}{c}\text { 3 months } \\
\text { Intervention, } n=84 \\
\text { Usual Care, } n=39\end{array}$} & \multicolumn{2}{|c|}{$\begin{array}{c}\text { 6 months } \\
\text { Intervention, } n=78 \\
\text { Usual Care, } n=37\end{array}$} \\
\hline & & $\begin{array}{l}\text { Change from } \\
\text { baseline (95\% } \\
\text { CI) }\end{array}$ & $\begin{array}{c}\text { p- } \\
\text { value }\end{array}$ & $\begin{array}{c}\text { Change from } \\
\text { baseline } \\
95 \% \mathrm{CI}\end{array}$ & $\begin{array}{c}\text { p- } \\
\text { value }\end{array}$ \\
\hline Adjusted Protein (g/kg IBW/d) & $\begin{array}{l}\text { Intervention } \\
\text { Usual Care }\end{array}$ & $\begin{array}{r}-0.07(-0.17 ; 0.03) \\
0.03(-0.11 ; 0.16)\end{array}$ & 0.2 & $\begin{array}{c}-0.15(-0.24 ;-0.05) \\
0.01(-0.12 ; 0.14)\end{array}$ & 0.03 \\
\hline Total Protein (g/d) & $\begin{array}{l}\text { Intervention } \\
\text { Usual Care }\end{array}$ & $\begin{array}{l}-5.8(-12.6 ; 1.0) \\
1.7(-7.7 ; 11.1)\end{array}$ & 0.2 & $\begin{array}{c}-11.3(-18.7 ;-4.8) \\
1.1(-8.4 ; 10.5)\end{array}$ & 0.02 \\
\hline Potassium (mmol/d) & $\begin{array}{l}\text { Intervention } \\
\text { Usual Care }\end{array}$ & $\begin{array}{c}-5.4(-10.7 ;-0.2) \\
2.7(-4.6 ; 9.9)\end{array}$ & 0.05 & $\begin{array}{l}-7.4(-12.8 ;-2.0) \\
2.9(-4.5 ; 10.3)\end{array}$ & 0.01 \\
\hline Phosphate (mg/d) & $\begin{array}{l}\text { Intervention } \\
\text { Usual Care }\end{array}$ & $\begin{array}{c}-128(-234 ;-22) \\
48(-98 ; 195)\end{array}$ & 0.03 & $\begin{array}{c}-168(-277 ;-58) \\
85(-64 ; 235)\end{array}$ & 0.003 \\
\hline Sodium (mg/d) & $\begin{array}{l}\text { Intervention } \\
\text { Usual Care }\end{array}$ & $\begin{array}{c}-344(-536 ;-153) \\
25(-240 ; 290)\end{array}$ & 0.02 & $\begin{array}{l}-417(-622 ;-210.6) \\
-29(-310 ; 252)\end{array}$ & 0.02 \\
\hline Healthy eating Index (HEI) & $\begin{array}{l}\text { Intervention } \\
\text { Usual Care }\end{array}$ & $\begin{array}{l}0.5(-1.7 ; 2.8) \\
0.7(-2.3 ; 3.8)\end{array}$ & 0.9 & $\begin{array}{l}1.7(-0.5 ; 3.9) \\
-0.1(-3.2 ; 2.9)\end{array}$ & 0.3 \\
\hline Serum potassium $(\mathrm{mmol} / \mathrm{L})$ & $\begin{array}{l}\text { Intervention } \\
\text { Usual Care }\end{array}$ & $\begin{array}{l}-0.13(-0.30 ; 0.05) \\
-0.17(-0.42 ; 0.07)\end{array}$ & 0.7 & $\begin{array}{l}0.01(-0.20 ; 0.23) \\
0.18(-0.12 ; 0.47)\end{array}$ & 0.3 \\
\hline $\begin{array}{l}\text { Meeting serum potassium } \\
\text { guidelines }(\%)\end{array}$ & $\begin{array}{l}\text { Intervention } \\
\text { Usual Care }\end{array}$ & $\begin{array}{l}0.87(0.80 ; 0.93) \\
0.86(0.75 ; 0.96)\end{array}$ & 0.9 & $\begin{array}{l}0.86(0.78 ; 0.93) \\
0.81(0.69 ; 0.94)\end{array}$ & 0.5 \\
\hline Serum phosphate $(\mathrm{mmol} / \mathrm{L})$ & $\begin{array}{l}\text { Intervention } \\
\text { Usual Care }\end{array}$ & $\begin{array}{c}-0.09(-0.21 ; 0.03) \\
-0.21(-0.38 ;- \\
0.05)\end{array}$ & 0.2 & $\begin{array}{l}-0.19(-0.32 ;-0.06) \\
-0.05(-0.23 ; 0.12)\end{array}$ & 0.2 \\
\hline $\begin{array}{l}\text { Meeting serum phosphate } \\
\text { guidelines }(\%)\end{array}$ & $\begin{array}{l}\text { Intervention } \\
\text { Usual Care }\end{array}$ & $\begin{array}{l}0.67(0.59,0.78) \\
0.75(0.62 ; 0.88)\end{array}$ & 0.4 & $\begin{array}{l}0.71(0.62 ; 0.81) \\
0.60(0.45 ; 0.75)\end{array}$ & 0.2 \\
\hline $\begin{array}{l}\text { Interdialytic weight gain } \\
\text { (kg/session) }\end{array}$ & $\begin{array}{l}\text { Intervention } \\
\text { Usual Care }\end{array}$ & $\begin{array}{l}0.03(-0.19 ; 0.26) \\
0.22(-0.09 ; 0.53)\end{array}$ & 0.3 & $\begin{array}{c}-0.06(-0.29 ; 0.18) \\
0.37(0.04 ; 0.69)\end{array}$ & 0.02 \\
\hline $\begin{array}{l}\text { Meeting interdialytic weight gain } \\
\text { guidelines }(\%)\end{array}$ & $\begin{array}{l}\text { Intervention } \\
\text { Usual Care }\end{array}$ & $\begin{array}{l}0.78(0.70 ; 0.87) \\
0.73(0.60 ; 0.86)\end{array}$ & 0.5 & $\begin{array}{l}0.89(0.82 ; 0.96) \\
0.62(0.47 ; 0.77)\end{array}$ & 0.001 \\
\hline $\begin{array}{l}\text { Nutritional status, well nourished } \\
\text { (PG-SGA) }\end{array}$ & $\begin{array}{l}\text { Intervention } \\
\text { Usual Care }\end{array}$ & $\begin{array}{l}\text { N/A } \\
\text { N/A }\end{array}$ & & $\begin{array}{l}0.88(0.81 ; 0.95) \\
0.92(0.84 ; 1.00)\end{array}$ & 0.5 \\
\hline $\begin{array}{l}\text { Prescribed Sodium Polystyrene } \\
\text { Sulfonate }(\%)\end{array}$ & $\begin{array}{l}\text { Intervention } \\
\text { Usual Care }\end{array}$ & $\begin{array}{l}0.91(0.86 ; 0.96) \\
0.90(0.82 ; 0.97)\end{array}$ & 0.7 & $\begin{array}{l}0.84(0.72 ; 0.97) \\
0.81(0.63 ; 0.98)\end{array}$ & 0.8 \\
\hline Number of phosphate binders & $\begin{array}{l}\text { Intervention } \\
\text { Usual Care }\end{array}$ & $\begin{array}{c}-0.05(-0.69 ; 0.58) \\
1.13(0.28 ; 1.98)\end{array}$ & 0.01 & $\begin{array}{c}-0.49(-1.19 ; 0.22) \\
0.71(-0.22 ; 1.64)\end{array}$ & 0.03 \\
\hline Prescribed diuretic (\%) & $\begin{array}{l}\text { Intervention } \\
\text { Usual Care }\end{array}$ & $\begin{array}{l}0.80(0.75 ; 0.86) \\
0.68(0.57 ; 0.80)\end{array}$ & 0.05 & $\begin{array}{l}0.80(0.73 ; 0.86) \\
0.75(0.65 ; 0.86)\end{array}$ & 0.5 \\
\hline $\begin{array}{l}\text { Number of anti-hypertensive } \\
\text { medications }\end{array}$ & $\begin{array}{l}\text { Intervention } \\
\text { Usual Care }\end{array}$ & $\begin{array}{l}-0.08(-0.28 ; 0.11) \\
0.03(-0.23 ; 0.29)\end{array}$ & 0.5 & $\begin{array}{l}-0.05(-0.29 ; 0.20) \\
-0.13(-0.46 ; 0.20)\end{array}$ & 0.7 \\
\hline Number of other medications & $\begin{array}{l}\text { Intervention } \\
\text { Usual Care }\end{array}$ & $\begin{array}{l}0.19(-0.36 ; 0.74) \\
0.28(-0.46 ; 1.01)\end{array}$ & 0.8 & $\begin{array}{c}-0.10(-0.84 ; 0.65) \\
0.16(-0.83 ; 1.14)\end{array}$ & 0.6 \\
\hline EQ-5D (utility) & $\begin{array}{l}\text { Intervention } \\
\text { Usual Care }\end{array}$ & $\begin{array}{c}0.00(-0.06 ; 0.06) \\
-0.004(- \\
0.09 ; 0.08)\end{array}$ & 0.9 & $\begin{array}{c}-0.04(-0.10 ; 0.02) \\
0.06(-0.02 ; 0.15)\end{array}$ & 0.03 \\
\hline $\begin{array}{l}\text { Quality Adjusted Life Years (no } \\
\text { baseline value) }\end{array}$ & $\begin{array}{l}\text { Intervention } \\
\text { Usual Care }\end{array}$ & $\begin{array}{l}\text { N/A } \\
\text { N/A }\end{array}$ & & $\begin{array}{ll}0.39 & (0.35,0.5) \\
0.42 & (0.41,0.5)\end{array}$ & 0.4 \\
\hline Serum Urea $(\mathrm{mmol} / \mathrm{L})$ & $\begin{array}{l}\text { Intervention } \\
\text { Usual Care }\end{array}$ & $\begin{array}{l}\text { N/A } \\
\text { N/A }\end{array}$ & & $\begin{array}{l}-1.3(-2.8 ; 0.2) \\
-0.7(-2.7 ; 1.3)\end{array}$ & 0.6 \\
\hline
\end{tabular}




\begin{tabular}{|c|c|c|c|c|c|}
\hline Serum albumin $(\mathrm{g} / \mathrm{L})$ & $\begin{array}{l}\text { Intervention } \\
\text { Usual Care }\end{array}$ & $\begin{array}{l}\text { N/A } \\
\text { N/A }\end{array}$ & & $\begin{array}{l}0.9(-0.3 ; 2.1) \\
1.4(-0.3 ; 3.0)\end{array}$ & 0.6 \\
\hline Serum bicarbonate $(\mathrm{mmol} / \mathrm{L})$ & $\begin{array}{l}\text { Intervention } \\
\text { Usual Care }\end{array}$ & $\begin{array}{l}\text { N/A } \\
\text { N/A }\end{array}$ & & $\begin{array}{c}0.9(0.1 ; 1.7) \\
1.0(0 ; 2.1)\end{array}$ & 0.8 \\
\hline Parathyroid Hormone (pg/ml) & $\begin{array}{l}\text { Intervention } \\
\text { Usual Care }\end{array}$ & $\begin{array}{l}\text { N/A } \\
\text { N/A }\end{array}$ & & $\begin{array}{l}5.7(-3.3 ; 14.7) \\
5.1(-6.9 ; 17.0)\end{array}$ & 0.9 \\
\hline HbA1c (diabetics only) & $\begin{array}{l}\text { Intervention } \\
\text { Usual Care }\end{array}$ & $\begin{array}{l}\text { N/A } \\
\text { N/A }\end{array}$ & & $\begin{array}{c}0.01(-0.36 ; 0.55) \\
-0.37(-1.13 ; 0.38)\end{array}$ & 0.2 \\
\hline Pre-dialysis systolic BP (mmHg) & $\begin{array}{l}\text { Intervention } \\
\text { Usual Care }\end{array}$ & $\begin{array}{l}\text { N/A } \\
\text { N/A }\end{array}$ & & $\begin{array}{l}0.9(-4.0 ; 5.8) \\
1.5(-5.0 ; 8.1)\end{array}$ & 0.9 \\
\hline Pre-dialysis diastolic BP (mmHg) & $\begin{array}{c}\text { Intervention } \\
\text { Usual Care }\end{array}$ & $\begin{array}{l}\text { N/A } \\
\text { N/A } \\
\end{array}$ & & $\begin{array}{c}-0.7(-3.5 ; 2.1) \\
0.34(-3.40 ; 4.08)\end{array}$ & 0.6 \\
\hline Post-dialysis systolic BP (mmHg) & $\begin{array}{c}\text { Intervention } \\
\text { Usual Care }\end{array}$ & $\begin{array}{l}\text { N/A } \\
\text { N/A }\end{array}$ & & $\begin{array}{l}-2.0(-7.5 ; 3.6) \\
-0.4(-7.8 ; 7.0) \\
\end{array}$ & 0.7 \\
\hline Post-dialysis diastolic BP (mmHg) & $\begin{array}{c}\text { Intervention } \\
\text { Usual Care }\end{array}$ & $\begin{array}{l}\text { N/A } \\
\text { N/A } \\
\end{array}$ & & $\begin{array}{l}-3.4(-6.0 ;-0.8) \\
-1.3(-4.7 ; 2.2) \\
\end{array}$ & 0.3 \\
\hline $\begin{array}{l}\text { Having } \geq 1 \text { consultation with } \\
\text { dietitian during study (OR) }\end{array}$ & $\begin{array}{l}\text { Intervention } \\
\text { Usual Care }\end{array}$ & $\begin{array}{l}0.69(0.55 ; 0.83) \\
0.74(0.55 ; 0.93)\end{array}$ & 0.7 & $\begin{array}{l}0.79(0.67 ; 0.92) \\
0.73(0.54 ; 0.93)\end{array}$ & 0.6 \\
\hline
\end{tabular}

$\mathrm{CI}$ - confidence interval; effect - mean change from baseline, adjusted for health district (stratification variable) or percentage adjusted baseline status and health district; N/A: for data that was only collected at baseline and 6 months 
Table 4: Recommendations for development of Phase $2 \mathrm{~b}$ trial of KIDNEYTEXT

\begin{tabular}{|c|c|}
\hline Design & Adaptive, cluster randomization by dialysis unit ${ }^{22}$ \\
\hline $\begin{array}{l}\text { Potential } \\
\text { recruitment } \\
\text { strategies }\end{array}$ & $\begin{array}{l}\text { - Pragmatic study design that is embedded within current } \\
\text { renal nutritional care }{ }^{22,23} \\
\text { - Consent process facilitated through renal clinicians (i.e. } \\
\text { dietitians, nurses, nephrologists), rather than specific } \\
\text { research staff }{ }^{22,24} \\
\text { - Additional online portal patients can opt into without } \\
\text { clinicians } \\
\text { - Use of a care givers' mobile phone if necessary or } \\
\text { preferred by the patient }\end{array}$ \\
\hline Follow-up & 6 month intervention with 3 month of follow-up \\
\hline Blinding & Outcome assessors to be blinded \\
\hline Interventions & $\begin{array}{l}\text { Three mobile phone text messages per week for } 6 \text { months. } \\
\text { Enhancement of personalisation of text messages by: } \\
\text { - participants being able to change the text message topics } \\
\text { they receive throughout the intervention, or } \\
\text { - having two-way communication with a dietitian or trained } \\
\text { health professional. }\end{array}$ \\
\hline Primary outcome & $\begin{array}{l}\text { Dietary related markers of cardiovascular disease risk. Such as: } \\
\text { - potassium management (i.e. serum targets and use of } \\
\text { medications) } \\
\text { - phosphate management (i.e. serum targets and use of } \\
\text { medications) and } \\
\text { - fluid management (i.e. interdialytic weight gain) }\end{array}$ \\
\hline
\end{tabular}


Figure 1: Study flow diagram

Figure 2: Proportion of participants adhering to $\geq 3$ renal dietary guidelines (nonadjusted) with $95 \%$ confidence intervals. 


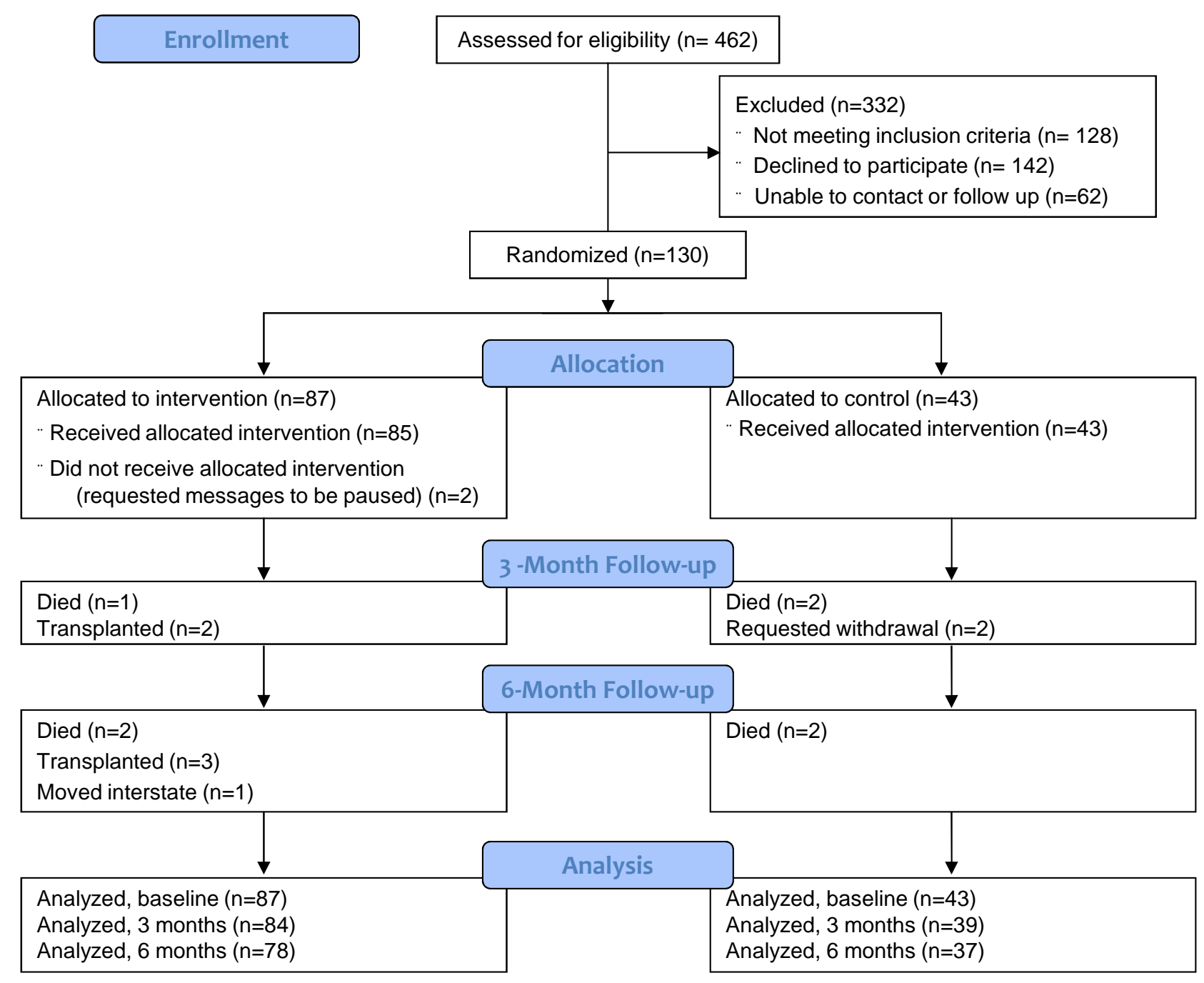




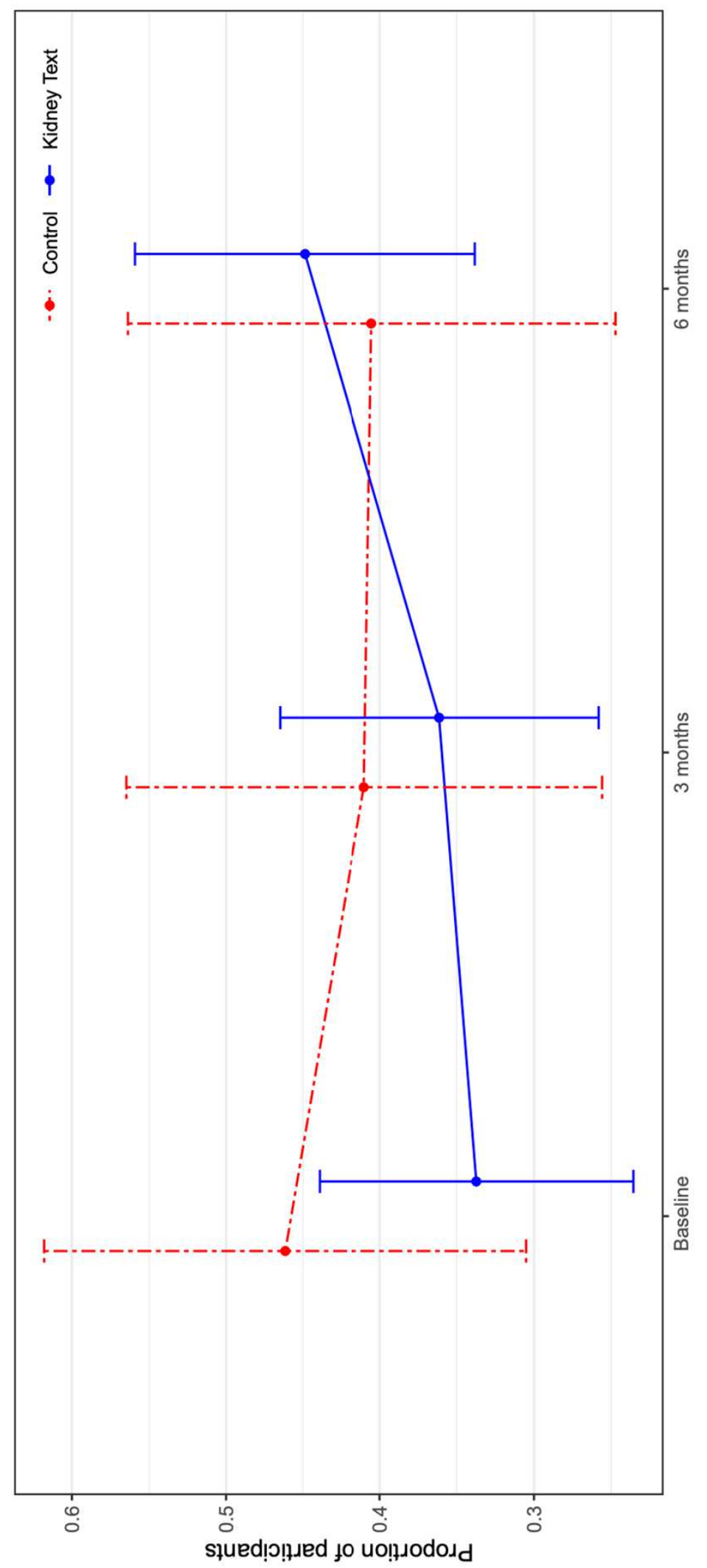

